\title{
Thinking about research based on a seven-point principle?
}

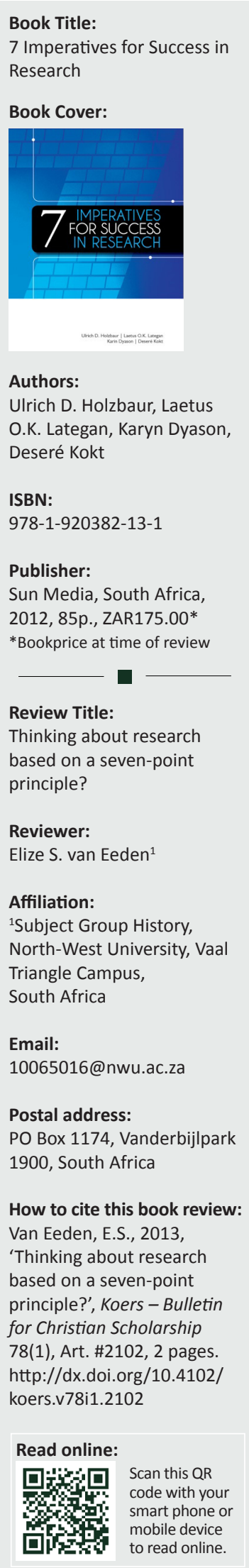

\section{Content summary}

The 7 Imperatives for Success in Research brings to mind some other ' $7 \mathrm{~s}$ ' one is able to find in the human made world of business, as a form of continuation of this number's respected position in the natural and the religious world. If the '7 imperatives for success' are not in management, then it's the 'how to' of successful business leadership or in customer satisfaction and even how to be business revolutionaries. These imperatives are usually voiced by highly successful professionals. The imperatives are certainly not intended as instant recipes for sometimes very complicated and challenging issues and activities, but actually as hints on essentialities in specific fields, and how people with experience and knowledge in such a field try to concisely but meaningfully transfer gained knowledge and life wisdom to the next generation.

All four authors involved in compiling the 7 Imperatives for Success in Research do have the credentials: all are amply blessed with the know-how and skills gained from years in respected positions in research environments. This 85-page publication consists of seven concise chapters, each dealing with one research imperative:

1. Understand research and its environment

2. Personal development and career advancement

3. Be the 'ethical' researcher

4. Develop your planning skills

5. Present your research results

6. Get published

7. Go beyond - The ivory tower

\section{Merits of the publication - An assessment}

Current research challenges, as well as the needs to educate the next generation of researchers and equally develop and build the capacity of researchers on all levels of research activities, have inspired the authors to define these seven imperatives as vital to successful research. The seven imperatives indeed cover the 'how-to' questions researchers frequently ask and which most only understand after many years of having engaged in research in a 'rest in peace'-like mode.

\section{Target reader indication}

The book is especially aimed at early career researchers, but claims to also be of value to research managers and research administrators. The authors in fact express the hope that leaders in the diverse research environments 'will engage with the book in such a rigorous manner that they will provide feedback' to the authors so that they can 'update and expand on the ideas and advice' in the book.

However, the approach to topics such as development of a research career and dissemination of research in 7 Imperatives for Success in Research is very basic, simplistic, cryptic and certainly not user-friendly. Perhaps it only serves in some way as a beginner's 'guideline' for researchers-tobe? If that is the core focus and the literature has indicated a substantial market for it, the authors should stick to the early researcher principle. The authors should not try to be everything to every corpus of the research environment because research environments can extensively differ from one another.

Questions that spontaneously arise from 7 Imperatives for Success in Research are: Should it only be utilised in a one-on-one basis by early career researchers, should it serve a purpose in training post-graduate researchers in workshops, should it serve as a module in a curriculum, or what? What gap in advice on ways of starting a research career and go about conducting research will this contribution fill? 


\section{General comments}

\section{Research approach - Learn by example}

In order to situate the book within the research environment, the authors of 7 Imperatives for Success in Research should have been explicit on why such a publication is needed when there are already several on the market. Also, they do not touch on what can be learned from past and current literature on research in building a research career. What appears totally absent are the author's foci and how readers should approach the content of the book. The gap in the market the authors intend to fill (their problem question so to speak) should have been more explicit. In this regard the authors could have explained what they want to uniquely accomplish, differently from what so many others have already published in the field, such as Francine Berman (1993), Michelle N. Bushey et al. (2001), Sara Delamont and Paul Atkinson (2004), Alan Johnson (2011) and Kierstin Wesolowski (2011). The authors mainly use one source (namely that of one of the co-authors, Laetus Lategan) in all instances.

\section{Educational}

The authors appear to want to 'educate' potential and existing researchers on seven important imperatives without at all explaining how this publication with its unusual content structuring should be educationally and instructively approached to be of value. The bare minimum of information is concisely shared in sections in each chapter after which several assignments as discussion or 'homework' follow. Minimal follow-up hints, responses, additional reading suggestions or guidelines are provided.

\section{Technical}

Leaving 'empty spaces' for assignments in a publication of this nature for practitioners in the wide research environment to complete or debate on means the book reminds one more of an interactive student study guide usable for a limited period in the training process.

The overall impression one is left with of this well-meant publication is that it could be quite useful provided that the authors address the shortcomings indicated. In essence, the not-so-welcome critique boils down to two main concerns: insufficient information and lack of guidance as to how to approach and utilise the book. An 'early career researcher' might just perceive it as maze of incompletely structured and informed topics.

\section{References}

Berman, F., 1993, 'Building a research career', in A. Redelfs (ed.), CRA-W: Career mentoring workshops, pp. 1-56, CRA-W, San Diego.

Greenfield, T., 1996, Research Methods. Guidance for post graduates, Arnold, London.

Bushey, M.N., Lycan, D.E. \& Videtich, P.E., 2001, How to Get a Tenure-Track Position at a Predominantly Undergraduate Institution: Advice for those in the scientific fields, Council on Undergraduate Research, Washington, DC.

Delamont, S., Atkinson, P. \& Parry, O., 2004, Supervising the doctorate: $A$ guide to success, 2nd edn., Open University Press, Berkshire, UK.

Johnson, A.M., 2011, Charting a course for a successful research career. A guide for early career researchers, 2 nd edn., Elsevier, Amsterdam.

Wesolowski, K., 2011, 'Career Tracks: Strategies for developing early researcher careers - and getting funded', Neurology Today 11(2), 14-15. http://dx.doi.org/10.1097/01.NT.0000394628.22919.f0 